\title{
Pediatric cervical spine injuries with neurological deficits, treatment options, and potential for recovery
}

\author{
Belal Elnady ${ }^{1, *}$, Essam El-Morshidy ${ }^{1}$, Mohamed El-Meshtawi ${ }^{1}$, and Ahmed Shawky ${ }^{1,2}$ \\ 1 Department of Orthopedic and Trauma Surgery, Assiut University Medical School, 71111 Assiut, Egypt \\ 2 Department of Spine Surgery, HELIOS Klinikum Erfurt, 99089 Erfurt, Germany
}

Received 19 December 2016, Accepted 26 May 2017, Published online 6 September 2017

\begin{abstract}
Purpose: The purpose of the present study was to highlight the challenges in managing cervical spine injuries in children with neurological deficits.

Introduction: Cervical spine injuries in children are relatively rare. Pattern, severity, and level of these injuries are age dependent. Neurological deficits in young children are uncommon and usually have a good potential for recovery. Patients and methods: This report includes four cases with pediatric cervical spine injuries with variable degrees of spinal cord injuries and neurological deficits. All the four patients were five years old or younger at the time of injury. Those patients were presented with different patterns of injuries and the treatment was customized for every patient. Marked neurological improvement occurred in all patients at the last follow-up.

Conclusion: The treatment of pediatric cervical spine injuries should be individualized. Children with stable injuries would do well with non-operative treatment while operative treatment is recommended when the indication is appropriate and the expertise is available. Neurological deficits due to spinal cord injuries in pediatric patients have a high potential for recovery, provided that adequate management is considered.
\end{abstract}

Key words: Pediatric spinal injuries, Pediatric cervical trauma, Pediatric spinal cord injury.

\section{Introduction}

Cervical spine injuries in children are relatively rare, representing only about $2 \%$ of all spine trauma [1]. Pattern, severity, and level of these injuries are age dependent [2]. Evaluation and clearance of cervical spine injuries in children is obviously a difficult job due to lack of cooperation during examination and imaging procedures.

Neurological deficits in young children are uncommon and usually have a good potential for recovery. However, it carries the risk of catastrophic permanent neurological disability [3].

\section{Case 1}

A 16-month-old boy presented to the emergency room following a motor vehicle accident. He sustained a traumatic rotary subluxation of $\mathrm{C} 1 / 2$ (Fielding type 2) combined with a C3/4 disco-ligamentous injury. Neurological examination revealed a left-sided hemiparesis. Under general anesthesia, closed reduction was achieved through controlled axial traction of the head under image intensifier to avoid over-distraction at

\footnotetext{
*Corresponding author: belalelnady83@gmail.com
}

the $\mathrm{C} 3 / 4$ disco-ligamentous injury. Then rotation of the head to the left completed the reduction with an audible click. Immobilization in a Minerva cast was done. Three weeks later, the cast was replaced with a customized Minerva orthosis, which was in place for another three weeks. The neurological deficit progressively improved such that the child was almost neurologically normal at six weeks follow-up. Follow-up magnetic resonance imaging (MRI) after three months showed complete regression of the spinal cord edema, reduction of the facet joint on both sides, and complete healing of the $\mathrm{C} 3 / 4$ disco-ligamentous injury. At six months follow-up, complete recovery of the neurological deficit was evident with painless normal movement of the cervical spine in all directions (Figures 1 and 2).

\section{Case 2}

A four-year-old boy presented to the emergency room following a motor vehicle accident. Neurological examination revealed complete quadriplegia and radiological examination revealed $\mathrm{C} 3 / 4$ subluxation. MRI revealed extensive cord edema opposite to $\mathrm{C} 3 / 4$ levels. Under general anesthesia, closed reduction was tried guided by image intensifier to avoid 

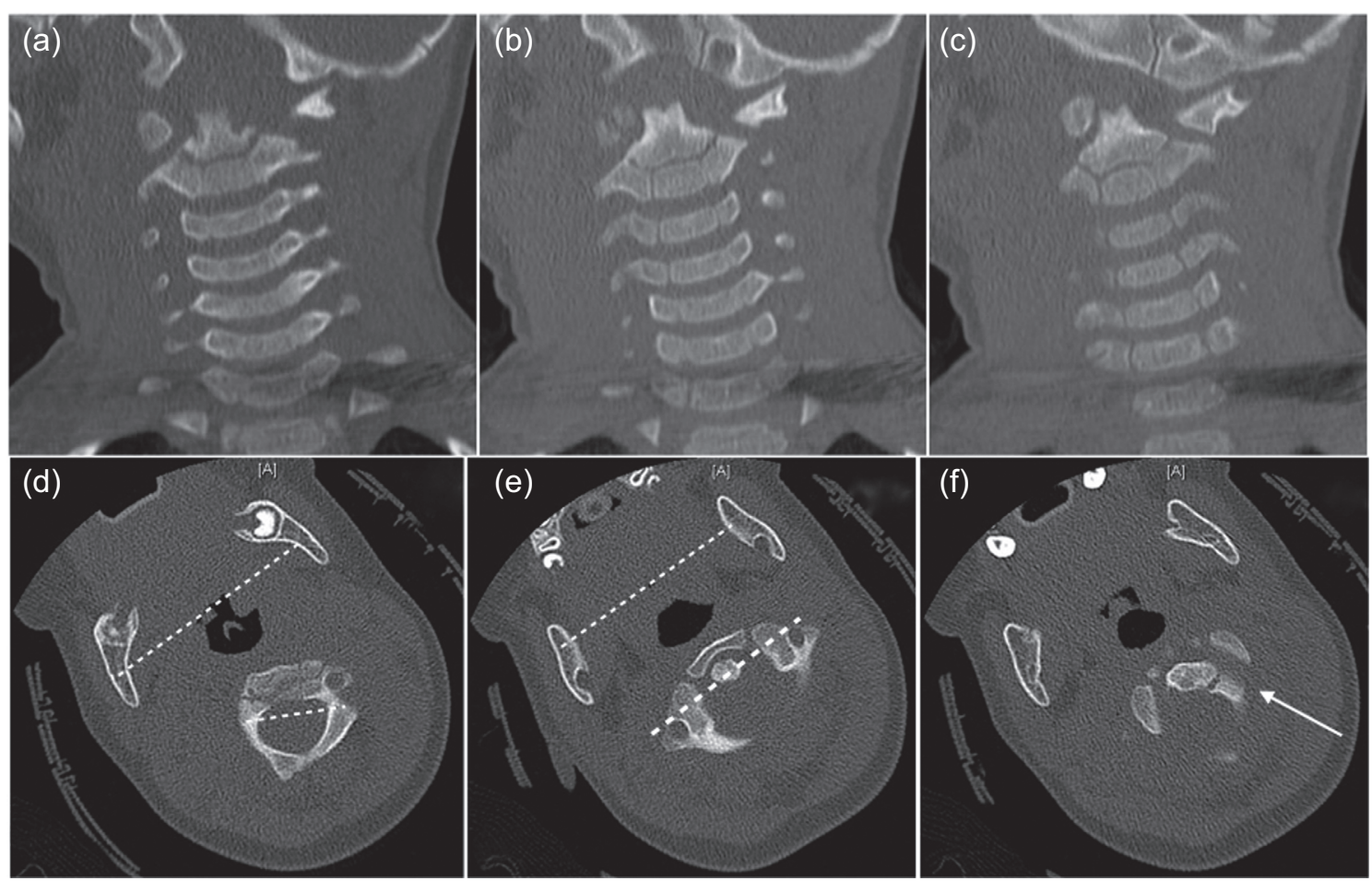

Figure 1. Case 1: A 16-month-old boy who sustained a motor vehicle accident. (a-c) Pre-reduction computed tomography (CT) scans showing the asymmetrical distance between dens and $\mathrm{C} 1$ lateral mass on both sides. (d) The difference between the transverse axis of the skull and $\mathrm{C} 2$. (e) The alignment of the transverse axis of $\mathrm{C} 1$ and skull. (f) The dislocated $\mathrm{C} 1 / 2$ joint on the left side (arrow).

over-traction. The reduction was unstable with resubluxation of $\mathrm{C} 3 / 4$, hence, the child was planned for operative intervention. Through a posterior approach, the subluxed $\mathrm{C} 3 / 4$ facet was reduced using a micro-dissector, then fixation was done using a cerclage wire through the spinous process of $\mathrm{C} 2-\mathrm{C} 4$ as there was an incidental fracture of the $\mathrm{C} 3$ spinous process. Decortication of $\mathrm{C} 2-\mathrm{C} 4$ laminae was done using a burr and then local bone graft was added. Postoperative X rays showed maintained reduction and a rigid collar was applied for six weeks. At the last follow-up one year after surgery, the child was walking unsupported with mild spasticity in his legs with reasonable hand function. Radiological evaluation revealed solid fusion between C2-C4 (Figure 3).

\section{Case 3}

A five-year-old boy was presented to the outpatient clinic with a history of a motor vehicle accident six months previously which resulted in traumatic $\mathrm{C} 1 / 2$ instability with incomplete quadriplegia. He had an operation in another hospital during which he had a non-instrumented $\mathrm{C} 1 / 2$ fusion using iliac bone graft and absorbable sutures. Neurological examination revealed Frankle $\mathrm{C}$ quadriparesis, while radiological evaluation showed persistent $\mathrm{C} 1 / 2$ instability with $\mathrm{C} 2 / 3$ posterior fusion (which may have resulted unintentionally from the previous surgery).

This child was planned for revision surgery. Through a posterior approach, reduction of $\mathrm{C} 1$ was done using a blunt bone micro-hook under the $\mathrm{C} 1$ arch. Fixation was done using a sublaminar cerclage wire under $\mathrm{C} 1$ arch and the fused $\mathrm{C} 2 / 3$ laminae. Decortication of $\mathrm{C} 1$ arch and $\mathrm{C} 2 / 3$ laminae was done using a burr and iliac bone graft was added. A rigid cervical collar was used for six weeks. At six-month follow-up, the child's neurological status was back to normal (Frankle D) and radiological examination showed solid $\mathrm{C} 1 / 2-3$ fusion (Figure 4).

\section{Case 4}

A four-year-old female child presented with neck pain and Frankle B quadriparesis with stable general condition following a fall from a three meter height. The plain radiograph showed $\mathrm{C} 2 / 3$ subluxation while MRI showed extensive spinal cord edema with disco-ligamentous injury at $\mathrm{C} 2 / 3$. Due to the marked instability of $\mathrm{C} 2 / 3$ levels in plain radiograph, anterior $\mathrm{C} 2 / 3$ discectomy and fusion using a cage and a cervical locked plate was done. At the last follow-up six months after surgery, the neurological status had improved to normal (Frankle D) with solid $\mathrm{C} 2 / 3$ fusion on the plain radiograph (Figure 5).

\section{Discussion}

The treatment of pediatric cervical spinal injuries has traditionally been conservative. Unstable pediatric spinal injuries 


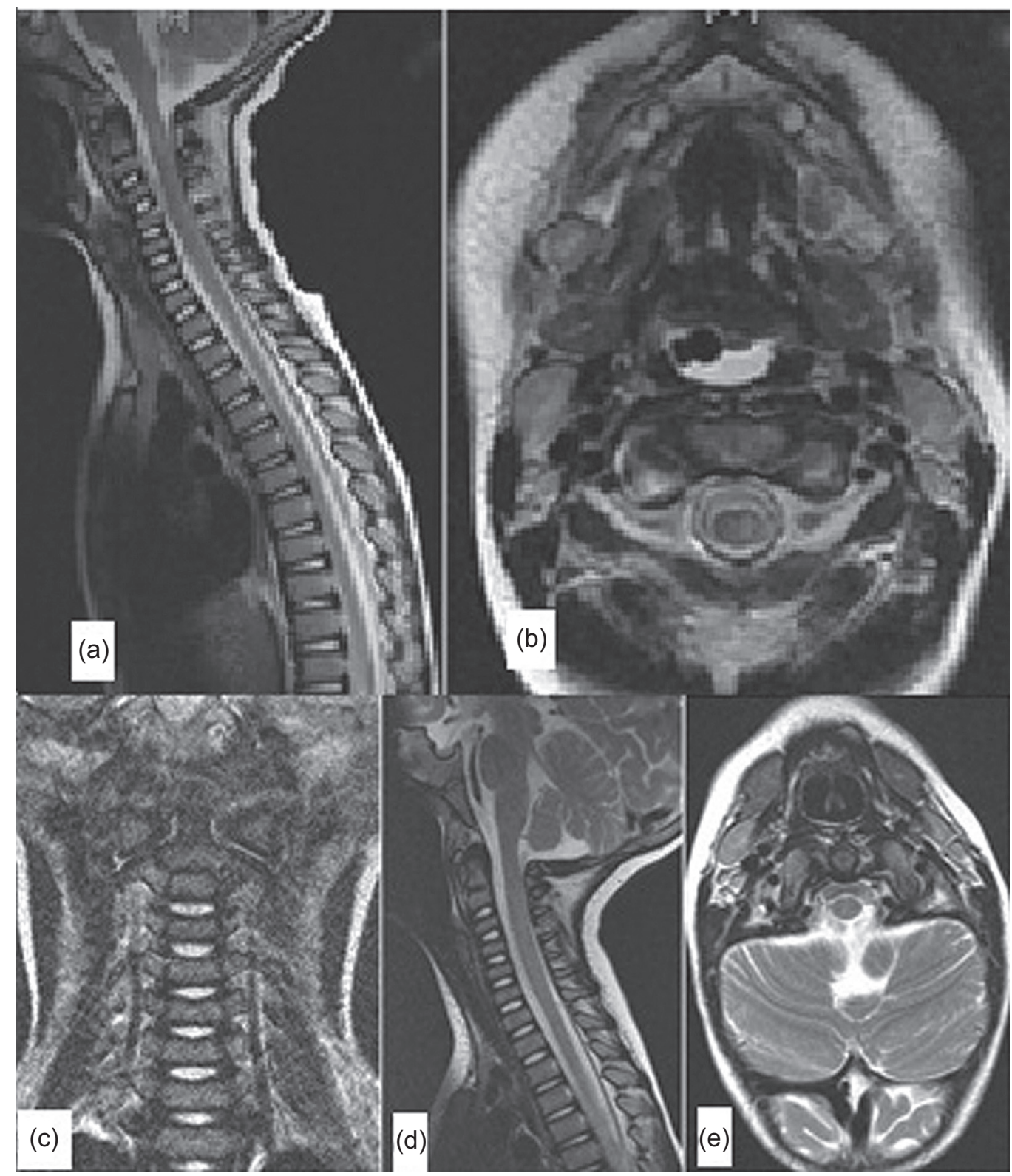

Figure 2. Case 1: $(\mathrm{a}, \mathrm{b})$ Pre-reduction MRI shows the disco-ligamentous injury at $\mathrm{C} 3 / 4$ level, and the spinal cord edema on the left side seen in axial cut. (c-e) Follow-up MRI shows the healing of the disco-ligamentous injury at $\mathrm{C} 3 / 4$ level, and complete subsidence of the spinal cord edema.

are increasingly being treated operatively [4-6]. Operative fixation in young children still has the challenge of appropriate implants and instrumentation.

Several fixation methods had been described for the fixation of pediatric cervical spine. This included wiring $[7,8]$, locked plates [6,9], rods and wires [8], and even sutures [5]. In this report, cerclage wire was preferred as a simple and effective method for posterior fixation. Children have very rapid healing power, and fusion is expected in a short time with low risk of metal failure. A conventional anterior cervical plate was used for anterior stabilization, however, a careful measurement of the plate and screw length is important.
Conservative treatment has a significant role in the management of stable pediatric cervical spine injury. In a study of unstable upper pediatric spine injury by Duhem et al. [8], 21 of 28 children were treated conservatively. The indications for surgery were: persistent instability in spite of halo traction, neurological deterioration, and irreducible fracture-dislocation. Parisini et al. [10] noted that conservative treatment was successful in stable fractures but failed in unstable injuries. Mortazavi et al. [11] treated 36 of 48 patients with multilevel spinal injury non-operatively, none of the conservatively treated patients needed surgical intervention in the follow-up period. 


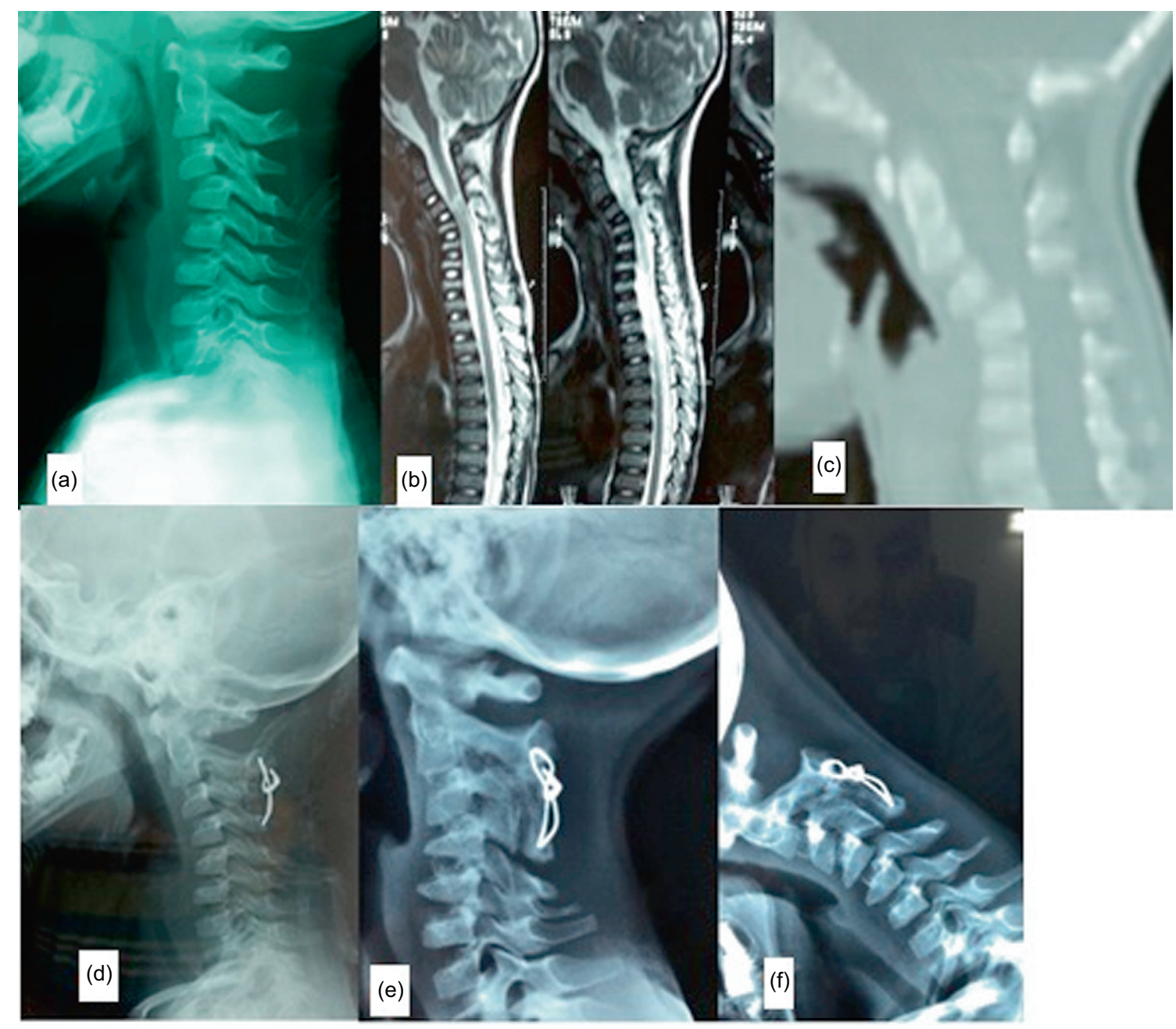

Figure 3. Case 2: A four-year-old boy. (a) Preoperative plain radiograph showing C3/4 subluxation, (b) preoperative MRI showing spinal cord edema, (c) preoperative sagittal CT scan confirming C3/4 subluxation, (d-f) one-year follow-up lateral, flexion, and extension X rays showing solid posterior $\mathrm{C} 2-\mathrm{C} 4$ fusion.

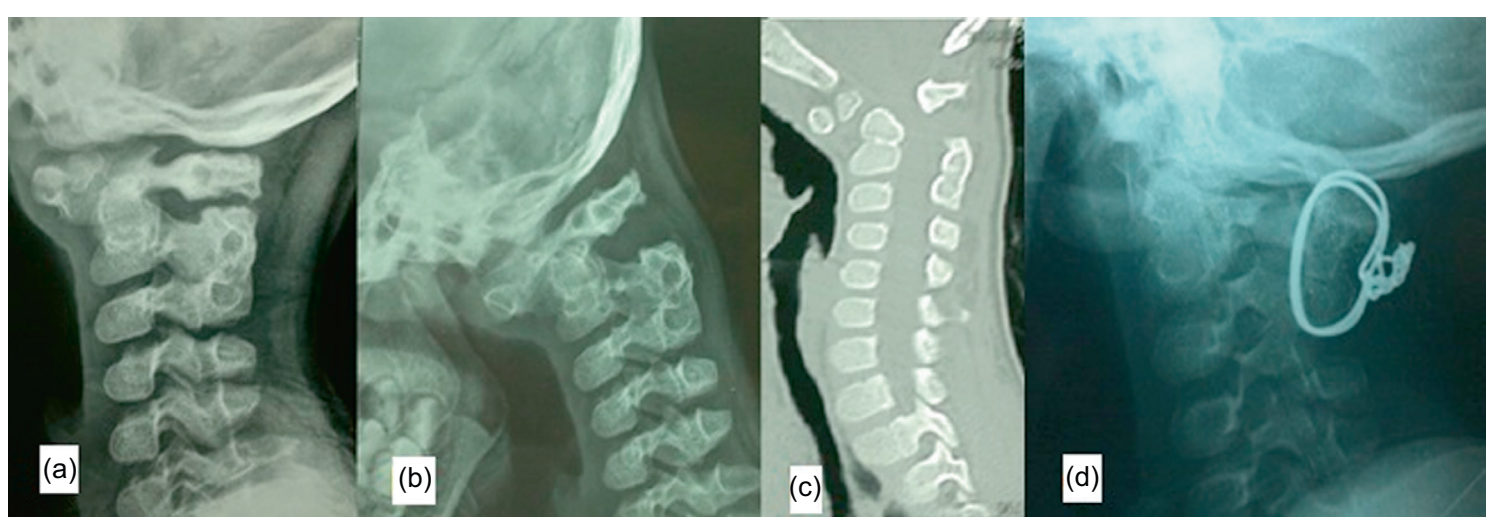

Figure 4. Case 3: A five-year-old boy. (a, b) Preoperative flexion and extension lateral cervical X rays showing C1/2 instability with clear pseudoarthosis and posterior $\mathrm{C} 2 / 3$ fusion, (c) preoperative sagittal CT scan showing anterior subluxation of C1, (d) postoperative $\mathrm{X}$ ray showing reduction of $\mathrm{C} 1$ with fixation of $\mathrm{C} 1 / 2-3$ with sublaminar cerclage wire. 


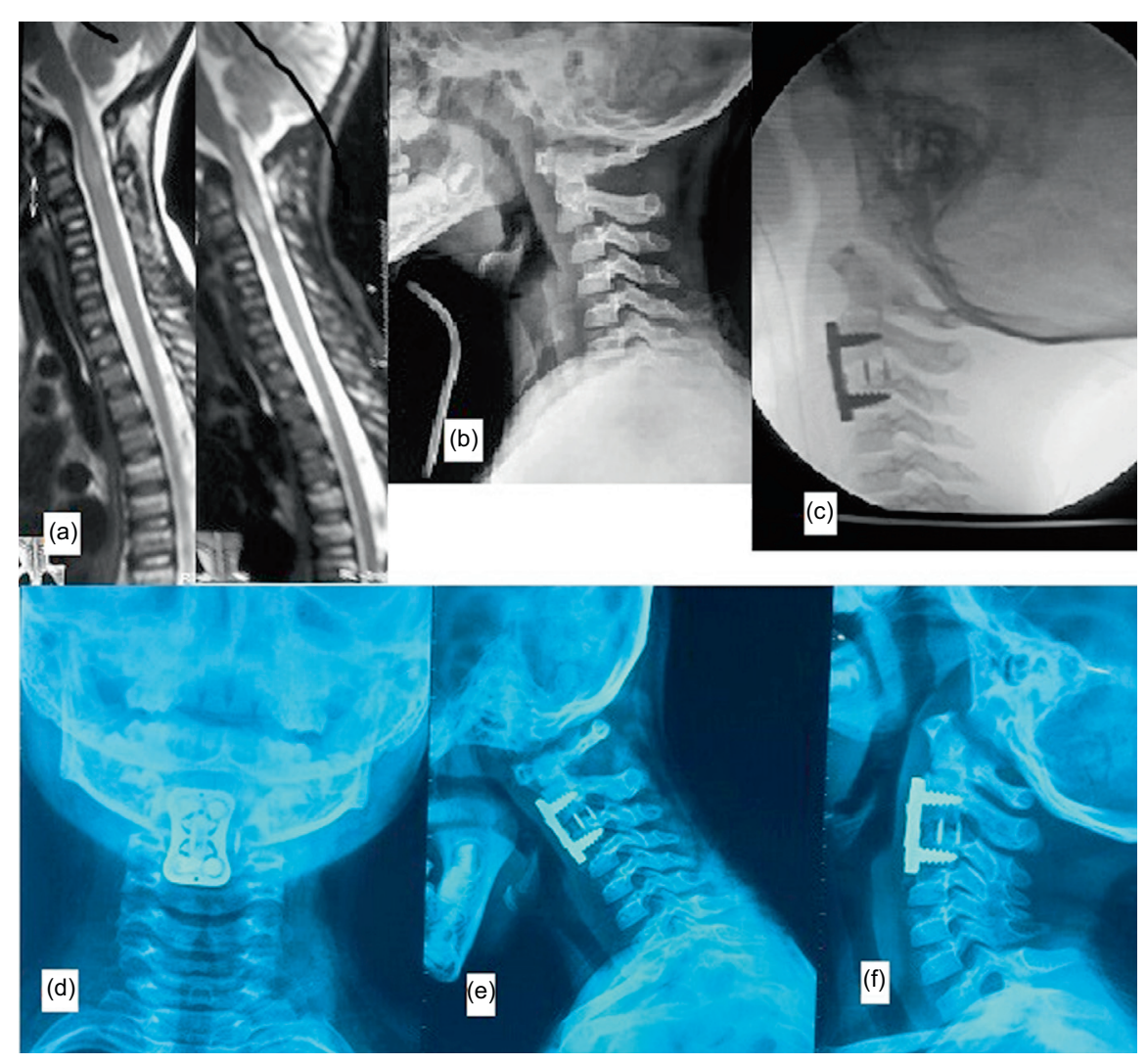

Figure 5. Case 4: A four-year-old girl. (a) Preoperative MRI showing disco-ligamentous injury at C2/3 level with spinal cord edema, (b) preoperative lateral $\mathrm{X}$ ray showing $\mathrm{C} 2 / 3$ subluxation, (c) intraoperative radiograph confirming the reduction of $\mathrm{C} 2 / 3$ with fixation using cage and cervical locked plate, (e-g) one-year follow-up anteroposterior (AP), flexion and extension lateral X rays showing solid fusion.

The prognosis for recovery from spinal cord injuries in pediatric patients is much better than the adult population. Children have rapid healing and more regeneration power of the nervous system [3, 4]. All patients in this report had spinal cord injury of variable degrees with marked improvement of all of them at the last follow-up. Several authors reported on complete neurological recovery in children after traumatic cervical spine injuries $[4,8,9]$.

\section{Conclusion}

The treatment of pediatric cervical spine injuries should be individualized. Children with stable injuries should do well with non-operative treatment often involving the use of customized orthosis. Operative treatment is recommended for unstable injuries when the indication is appropriate and the expertise is available. Neurological deficits due to spinal cord injuries in pediatric patients have a high potential for recovery provided that adequate management is considered.

\section{Conflict of interest}

All authors certify that they have no financial conflict of interest in connection with this article.

\section{References}

1. McGrory B, Klassen R, Chao E, Staeheli J, Weaver A (1993) Acute fractures and dislocations of the cervical spine in children and adolescents. J Bone Joint Surg Am 75(7), 988-995.

2. Bilston LE, Brown J (2007) Pediatric spinal injury type and severity are age and mechanism dependent. Spine 32(21), 2339-2347.

3. Mathison DJ, Kadom N, Krug SE (2008) Spinal cord injury in the pediatric patient. Clin Pediatr Emerg Med 9(2), 106-123.

4. Sakayama K, Kidani T, Matsuda Y, Sugawara Y, Shibata T, Yamamoto H (2005) A child who recovered completely after spinal cord injury complicated by $\mathrm{C} 2-3$ fracture dislocation: case report. Spine 30(10), E269-E271.

5. Hamoud K, Hershkovitz I, Hanani A, Marom L, Abbas J (2012) Internal stabilization of a flexion-distraction injury of the upper cervical spine of a toddler: a new technique and literature review. Spine 37(6), E400-E407.

6. Ramrattan NN, Öner FC, Boszczyk BM, Castelein RM, Heini PF (2012) Cervical spine injury in the young child. Eur Spine J 21(11), 2205-2211.

7. Hooley E, Chaput CD, Rahm M (2006) Internal fixation without fusion of a flexion-distraction injury in the lower cervical spine of a three-year-old. Spine J 6(1), 50-54.

8. Duhem R, Tonnelle V, Vinchon M, Assaker R, Dhellemmes P (2008) Unstable upper pediatric cervical spine injuries: report 
of 28 cases and review of the literature. Childs Nerv Syst 24(3), 343-348.

9. Chen Y, Wang X, Chen D, Liu X (2013) Surgical treatment for unilateral cervical facet dislocation in a young child aged 22 months old: a case report and review of the literature. Eur Spine J 22(3), 439-442.
10. Parisini P, Di Silvestre M, Greggi T (2002) Treatment of spinal fractures in children and adolescents: long-term results in 44 patients. Spine 27(18), 1989-1994.

11. Mortazavi MM, Dogan S, Civelek E, Tubbs RS, Theodore N, Rekate HL et al. (2011) Pediatric multilevel spine injuries: an institutional experience. Childs Nerv Syst 27(7), 1095-1100.

Cite this article as: Elnady B, El-Morshidy E, El-Meshtawi M \& Shawky A (2017) Pediatric cervical spine injuries with neurological deficits, treatment options, and potential for recovery. SICOT J, 3, 53 